\title{
TU/e ENMHONE

\section{Switched-beam array of dielectric rod antenna with RF-MEMS switch for millimeter-wave applications}

\section{Citation for published version (APA):}

Rousstia, M. W., Reniers, A. C. F., \& Herben, M. H. A. J. (2015). Switched-beam array of dielectric rod antenna with RF-MEMS switch for millimeter-wave applications. Radio Science, 50(3), 177-190.

https://doi.org/10.1002/2014RS005471

DOI:

10.1002/2014RS005471

Document status and date:

Published: 01/03/2015

\section{Document Version:}

Publisher's PDF, also known as Version of Record (includes final page, issue and volume numbers)

\section{Please check the document version of this publication:}

- A submitted manuscript is the version of the article upon submission and before peer-review. There can be important differences between the submitted version and the official published version of record. People interested in the research are advised to contact the author for the final version of the publication, or visit the $\mathrm{DOI}$ to the publisher's website.

- The final author version and the galley proof are versions of the publication after peer review.

- The final published version features the final layout of the paper including the volume, issue and page numbers.

Link to publication

\section{General rights}

Copyright and moral rights for the publications made accessible in the public portal are retained by the authors and/or other copyright owners and it is a condition of accessing publications that users recognise and abide by the legal requirements associated with these rights.

- Users may download and print one copy of any publication from the public portal for the purpose of private study or research.

- You may not further distribute the material or use it for any profit-making activity or commercial gain

- You may freely distribute the URL identifying the publication in the public portal.

If the publication is distributed under the terms of Article 25fa of the Dutch Copyright Act, indicated by the "Taverne" license above, please follow below link for the End User Agreement:

www.tue.nl/taverne

Take down policy

If you believe that this document breaches copyright please contact us at:

openaccess@tue.nl

providing details and we will investigate your claim. 


\section{Radio Science}

\section{RESEARCH ARTICLE \\ 10.1002/2014RS005471 \\ Switched-beam array of dielectric rod antenna with RF-MEMS switch for millimeter-wave applications}

Special Section:

Asia-Pacific Radio Science Conference 2013

\section{Key Points:}

- The coupling between the array element is sufficiently low

- Uniform antenna performance is observed for every scan angle

- High-gain and low sidelobe level antenna is realized

Correspondence to:

M. W. Rousstia,

m.w.rousstia@tue.nl

Citation:

Rousstia, M. W., A. C. F. Reniers, and M. H. A. J. Herben (2015), Switched-beam array of dielectric rod antenna with RF-MEMS switch for millimeter-wave applications, Radio Sci., 50, 177-190, doi:10.1002/2014RS005471.

Received 8 MAY 2014 Accepted 3 FEB 2015 Accepted article online 9 FEB 2015 Published online 12 MAR 2015

\author{
M. W. Rousstia' ' A. C. F. Reniers' ${ }^{1}$, and M. H. A. J. Herben' ${ }^{1}$ \\ ${ }^{1}$ Electromagnetics Group, Electrical Engineering Department, Eindhoven University of Technology, \\ Eindhoven, Netherlands
}

Abstract A conformal dielectric rod antenna array with operating frequency of $11.2 \mathrm{GHz}$ is investigated, designed, and measured. This antenna array is combined with a single pole double throw radio frequency microelectromechanical systems (RF-MEMS) switch to realize switched-beam performance. Moreover, this antenna array exhibits uniform radiation performance for different scan angles with no grating lobes. The characterization and measurement of the antenna system have been performed. The measured radiation pattern of the antenna in the anechoic chamber is in good agreement with the simulated antenna pattern. The measured antenna with the RF-MEMS switch has $13.5 \mathrm{dBi}$ realized gain, $-15 \mathrm{~dB}$ sidelobe level, $22^{\circ}$ half-power beamwidth, and 7.3\% (fractional) bandwidth (or $800 \mathrm{MHz}$ ) at $11.2 \mathrm{GHz}$.

\section{Introduction}

The increase in popularity of the dielectric rod with circular cross section is because of its wide bandwidth, shape, ability to create a symmetric radiation pattern, low polarization cross coupling, ease of fabrication, and low cost as reported by Kumar et al. [2010]. The rod antenna can be integrated directly to the monolithic microwave and millimeter-wave integrated circuits. The low-cost antenna for millimeter-wave applications, using the rod configuration made from dielectric material was proposed by Huang and Wang [2006]. The detailed analysis of the rod antenna was reported by Whitman et al. [2006] and Ando et al. [2005, 2003]. Some previous work utilized the horn waveguide as the excitation for the rod. The configuration with the horn waveguide is considered too bulky. Therefore, the patch-fed method is proposed here and considered as a plausible approach to realize a switched-beam antenna array. Moreover, high excitation efficiency to the rod using the (magnetic) ring slot was reported by Hanham and Bird [2008]. Another type of rod antenna employing the magnetic material was reported by Jordan et al. [2009].

Similar work to realize switched-beam operation was reported by Zelenchuk et al. [2013], Ouyang [2011], Sanada [2008], and Wilson et al. [2001]. Most of the antennas reported in these previous references from limited scan angle and nonuniform radiation performance, particularly for broad scan angle. Implementation of the switched-beam operation using multiple narrow beam antennas was also reported by Detrick and Rosenberg [1990]. Excellent uniformity of the radiation pattern and wide scan range is achieved through more complex and relatively large antenna structures as demonstrated by Karttunen et al. [2013] and Zhang and Hong [2012]. In addition to the dielectric rod, another possibility to realize the switched element of the array is by using a dielectric lens antenna, if the lateral dimensions of the lens can be made small. Michiels et al. [2011] reported a Luneburg lens design based on the simulation.

In Figure 1, a simulated pattern with the structure as in Huang and Edwards [2006] is shown to illustrate the nonuniformity of the radiation pattern. It can be observed that a reduction of $1.4 \mathrm{~dB}$ for the tilted antenna occurs. This reduction will be even larger for larger tilt. Furthermore, a squinted beam may also occur. An additional loss may also be added in the budget when the transmission line needs to reach the far rod. Therefore, a nonplanar array approach is proposed in this work to improve the overall performance of the antenna system. This conformal array of dielectric rods for producing a shaped or switched beam was proposed previously by Bird et al. [2008].

Combining the conformal rod antennas with the single pole double throw (SPDT) radio frequency microelectromechanical system (RF-MEMS) switch can realize a switched-beam antenna array with a uniform performance for each scan angle. The RF-MEMS switch is employed due to its high linearity, high isolation, and low-power consumption as described by Rebeiz [2003]. The complete antenna system is 


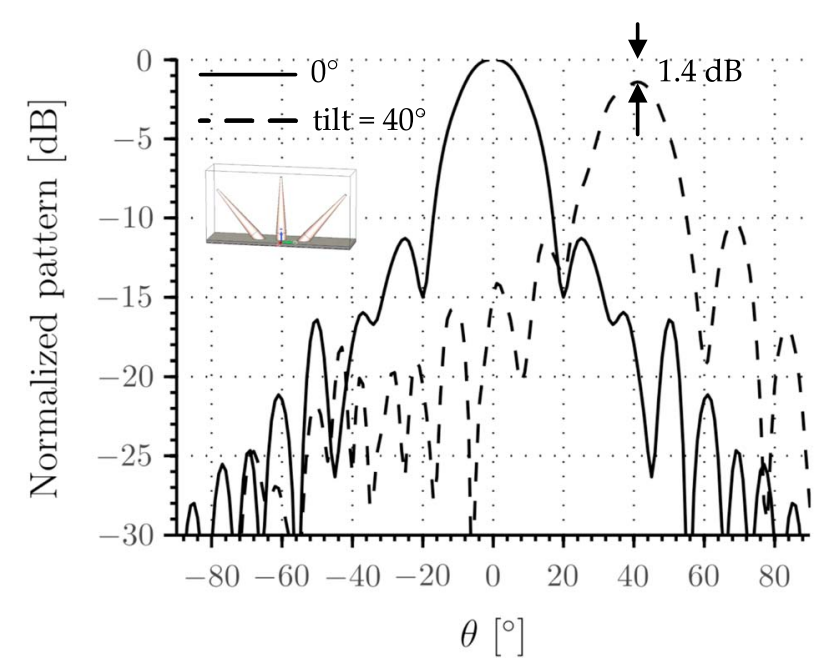

Figure 1. Nonuniform switched-beam radiation pattern by means of the nonplanar approach. a sufficient bandwidth at this frequency. Some promising substrates in terms of its low loss characteristic such as liquid crystal polymer are only available in a very thin panel. Stacking-up several panels may lead to blistering which leads to reduced yield result. For this reason, the substrate for the planar structure is chosen to be Nelco NX 9294 (i.e., fiber-reinforced Teflon), which is commercially available in a relatively thick panel. The NX 9294 has $\varepsilon_{r}$ of $2.94 \pm 0.04$ and $\tan \delta$ of 0.0022 at $10 \mathrm{GHz}$.

The foam material is used in the structure as a holder for the polystyrene rod $\left(\varepsilon_{r}=2.53 ; \tan \delta=0.0008\right.$ at $11 \mathrm{GHz}$ ) and as a foundation material for a support stand. A fixing disk slid into the hollow area between the waveguide and the rod gives robust construction of the rod structure. Figure 3 illustrates the structure and dimensions of the dielectric rod antenna. The type of the foam is Rohacell RC $31 \mathrm{HF}$ from Evonik Roehm $\mathrm{GmbH}$. From the measurement, its $\varepsilon_{r}$ is 1.046 , and its $\tan \delta$ is 0.0017 at $10 \mathrm{GHz}$. The adsorption of up to $25 \%$ water vapor leaves the dielectric properties of this material unchanged. This condition also makes this material suitable as the radome to give a strong protection to the array structure of the rod antenna. For the demonstration, the radome for this 3-D structure is not manufactured. However, for its low, i.e., near-to-vacuum, dielectric constant and low loss, the radome implementation will not influence the performance of the antenna.

\subsection{Planar Elements}

Figure 4 depicts the structure of the planar elements of the antenna. It is necessarily important to design and optimize the antenna performance with every detail of the structure taken into account. $A$ matched transmission line throughout the coaxial line, subminiature type A (SMA) connector, and coplanar waveguide (CPW) line deserves great attention. The careful design of, especially, the matched connector is to suppress the field discontinuity in the transition interface. A smooth transition is necessary to bridge between the evenly distributed electromagnetic fields at the coaxial end and the highly concentrated fields

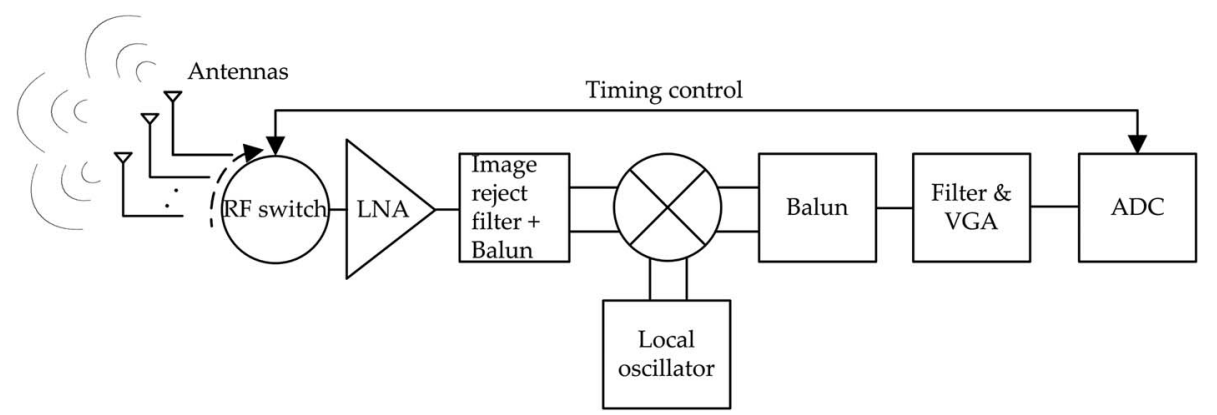

Figure 2. Antenna and RF-MEMS switch with the RF front-end system. $A D C=$ analog to digital converter; VGA = voltage gain amplifier. 


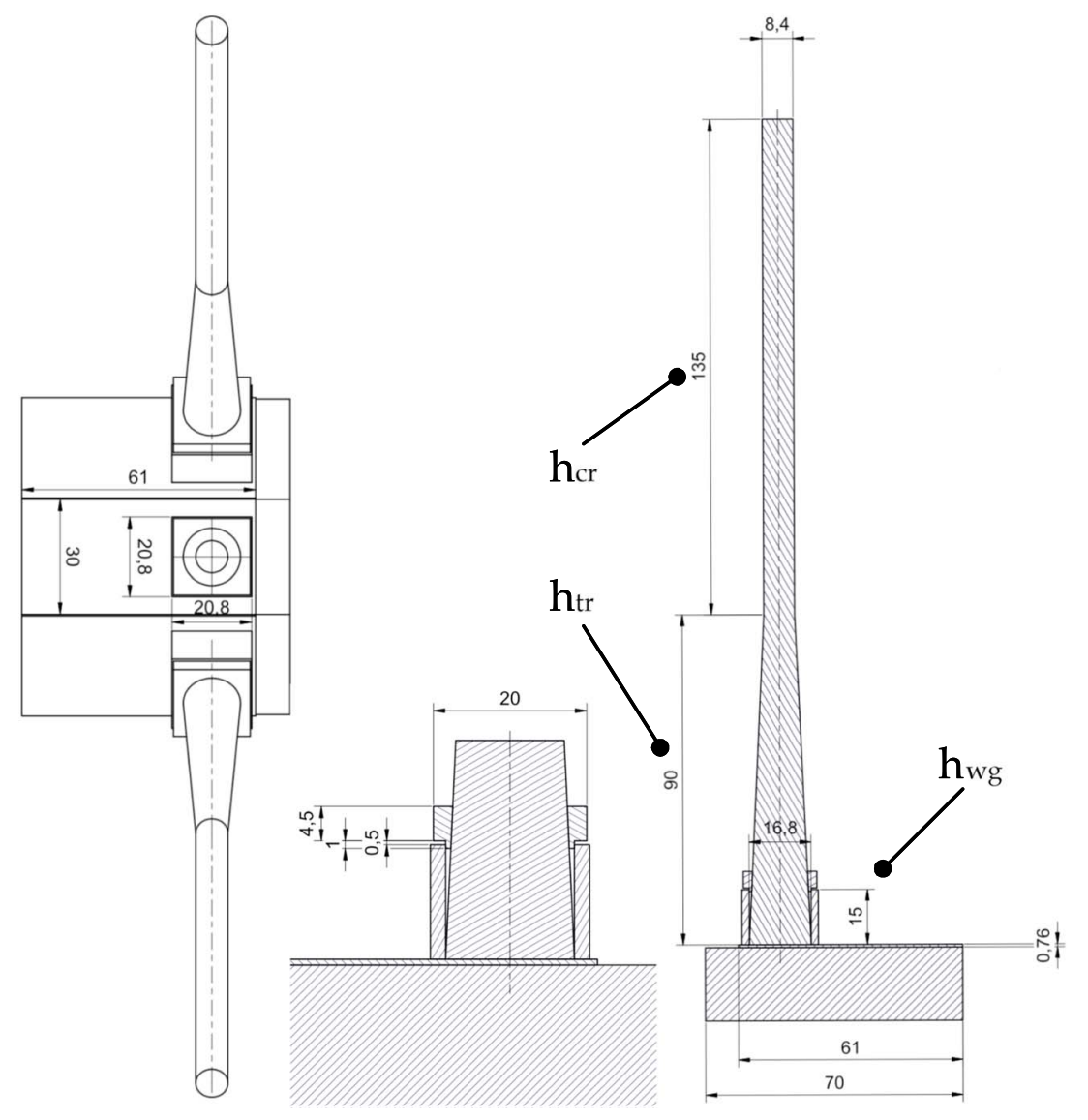

Figure 3. Structure and dimensions of the $11 \mathrm{GHz}$ conformal rod antenna (in millimeters).

of the even mode in the CPW. As a result, the transition interface exhibits no frequency dependency. For instance, the soldering between interconnection should not be the limiting factor of the overall system performance.

For the measurement convenience, the transition of the CPW from one side of the carrier substrate to the other side is incorporated. The transition from the lower side to the upper side of the substrate utilizes

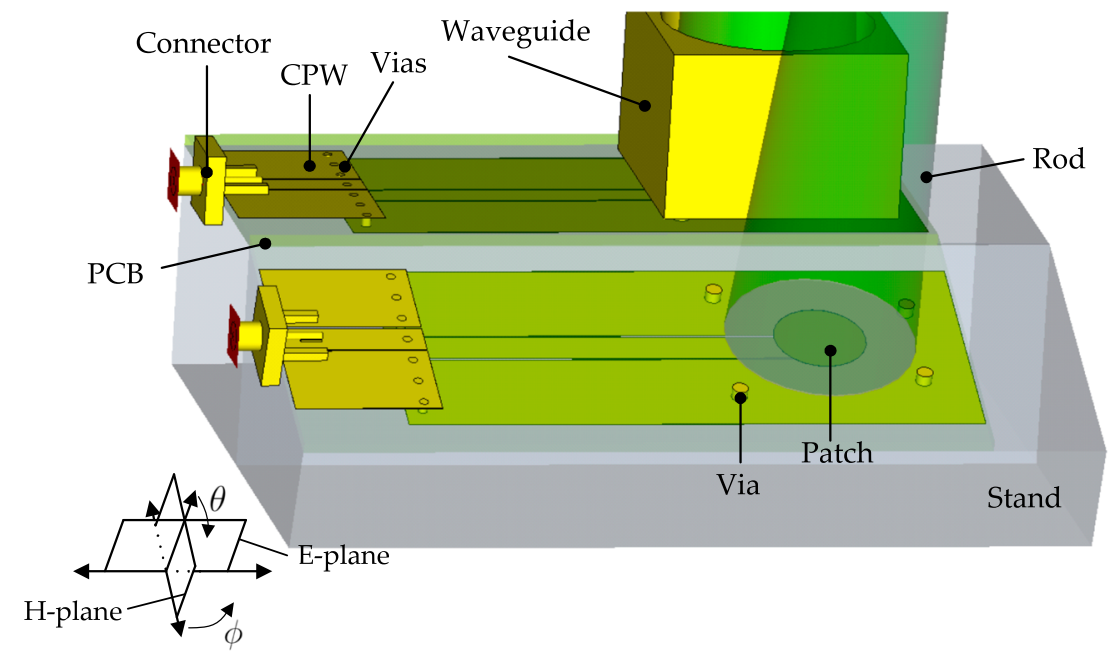

Figure 4. Structure of the planar elements. 


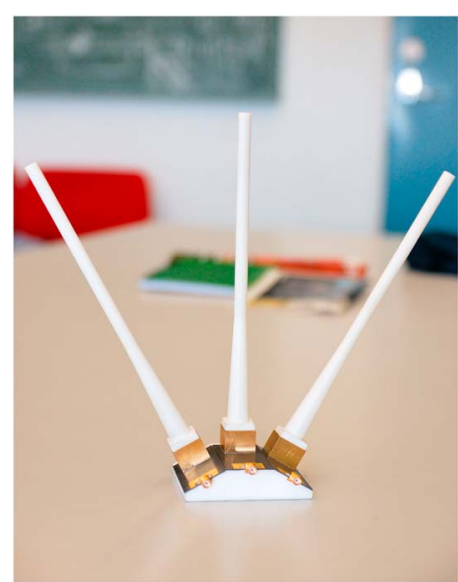

a)

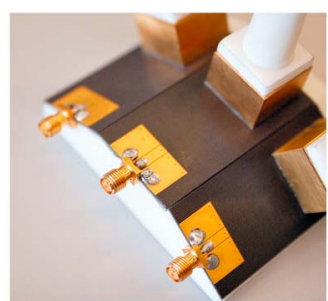

b)

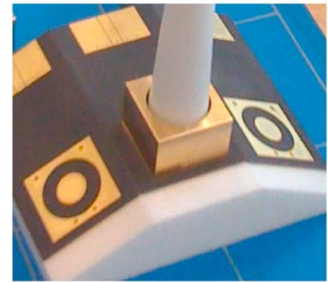

c)
Figure 5. Manufactured dielectric rod antenna array: (a) three rod elements made of polystyrene, (b) SMA connectors connected to the finite ground (FG) CPW, and (c) antenna assembly. several vias with a diameter of $0.25 \mathrm{~mm}$. These vias are separated with a pitch distance of $3 \mathrm{~mm}$. Important points in the via design are its inductive parasitic and undesired stub. As for $11 \mathrm{GHz}$ implementation, the challenge to properly construct a via becomes more pronounced than the implementation in lower frequencies. In addition to the signal via, some ground vias are employed to facilitate the proper return current at $11 \mathrm{GHz}$.

A circular patch with a diameter of $8.14 \mathrm{~mm}$ is used to excite the polystyrene rod. A $30^{\circ}$-tilted conformal antenna array is realized by means of separated printed circuit boards (PCB). Four through vias are responsible to level the voltage of the metallic waveguide (which is made of brass) and the CPW's ground. A proper design can avoid the undesired mode due to parallel plate construction between the waveguide and the ground plane. The manufactured rod antenna array is shown in Figure 5. The assembly of the brass waveguide itself is done by soldering it onto the copper trace on the PCB.

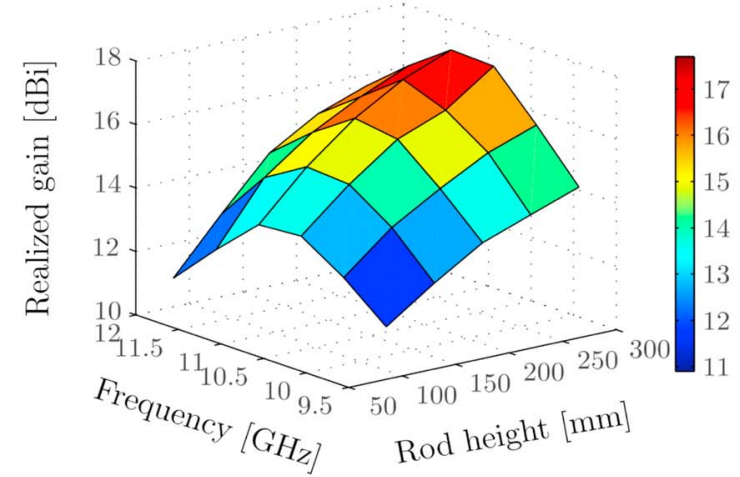

(a)

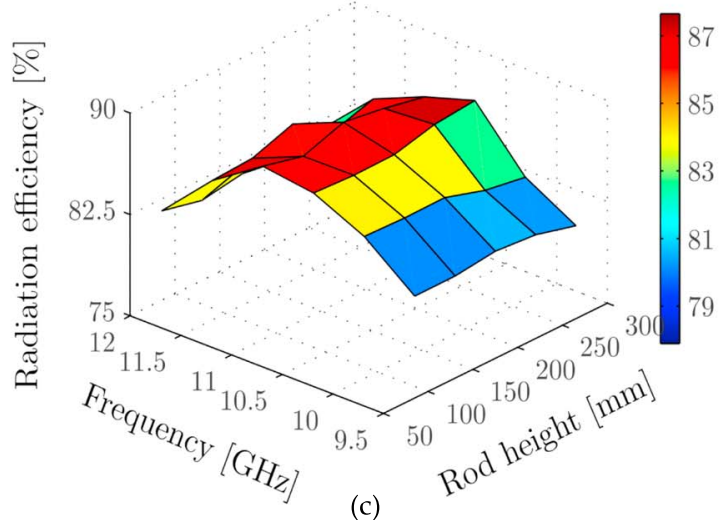

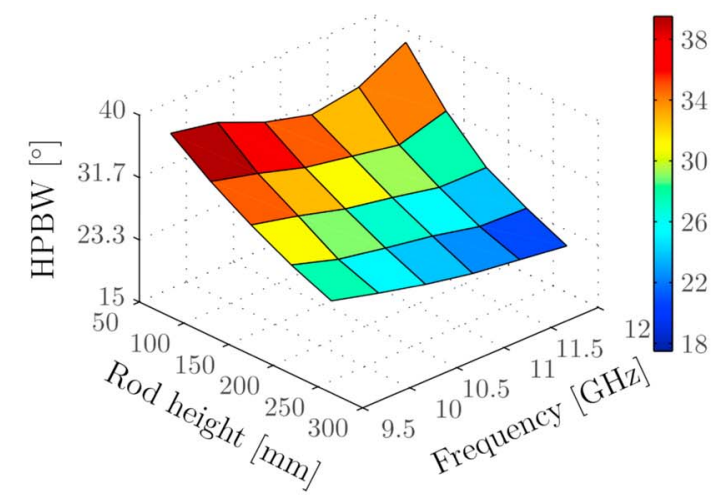

(b)

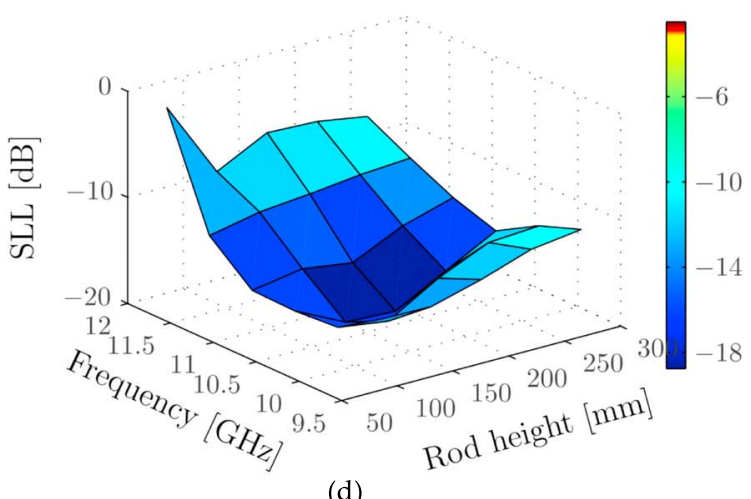

(d)

Figure 6. (a) Realized gain (at $\theta=0^{\circ}$ ), (b) half-power beamwidth for $\phi=90^{\circ}$, (c) total radiation efficiency, and (d) sidelobe level for $\phi=90^{\circ}$. The rod height is $h_{\mathrm{cr}}$ for the antenna demonstrator $\left(f_{o}=11 \mathrm{GHz}\right)$. 


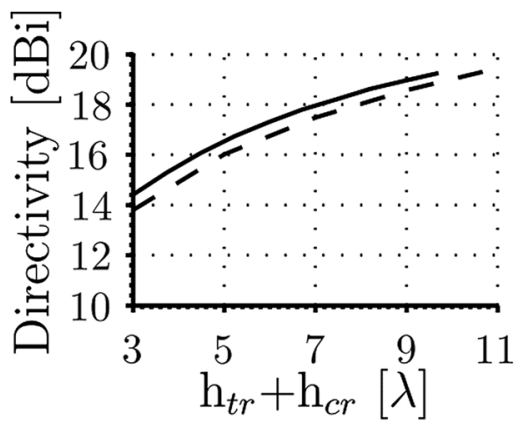

a)

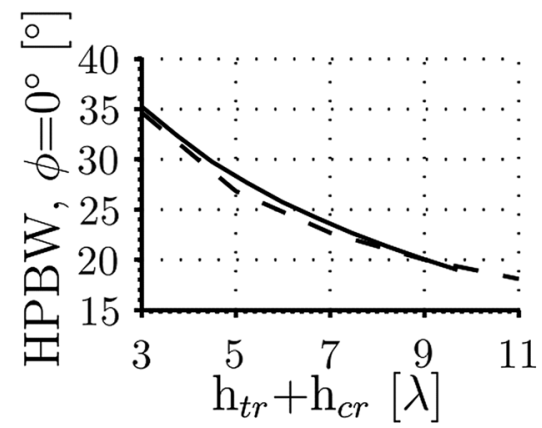

b)

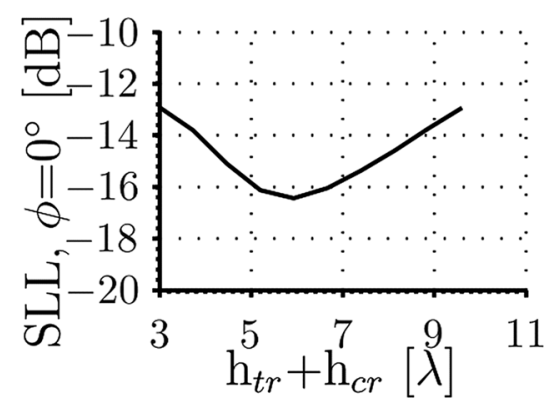

c)

Figure 7. General design template for various heights of the cylindrical rod $\left(h_{\mathrm{cr}}\right)$ : (a) the directivity, (b) half-power beamwidth for $\phi=0^{\circ}$, and (c) sidelobe level for $\phi=0^{\circ}$. The solid line is for the simulated value, and the dashed line is for the value from theoretical approximation in Kraus and Marhefka [2002].

\subsection{Parametric Study}

The measurement results of the manufactured antenna will be presented and compared with the numerical result. The realized gain, half-power beamwidth (HPBW), and sidelobe level (SLL) are of great importance in the switched-beam 3-D antenna array and thus are evaluated.

First, a summary of numerical results of rod antenna performance is illustrated in Figure 6 for varying rod's total height. It is observed that the antenna gain is improved proportionally with the rod's height. Nevertheless, the improvement saturates after certain value of height. This phenomenon is due to destructive addition between rays that remain guided (i.e., internally reflected) and rays that are early refracted in the dielectric rod. This trade-off that occurs between length and gain of the linearly profiled dielectric rod was originally described by Zucker [2007]. More recently, the topic was discussed by Ando et al. [2005]. It was reported that the curvilinearly profiled dielectric rod exhibits higher gain than the linearly profile rod does, for the same height. Furthermore, Hanham et al. [2011] reported that this trade-off could be overcome by profiling the rod and, at the same time, designing a more suitable element pattern.

In this work, the gain of the antenna was designed to be about $17 \mathrm{dBi}$ at $11 \mathrm{GHz}$ and is relatively constant over a $10 \%$ bandwidth, as shown in Figure 6 . The HPBW is kept below $30^{\circ}$ while the $\mathrm{SLL}$ is maintained around $-14 \mathrm{~dB}$ for a wide frequency band.

To generalize rod antenna performance, Figure 7 provides the directivity, HPBW, and SLL of the antenna radiator for different total heights of the dielectric rod. Note that $h_{\mathrm{tr}}$ is kept constant while $h_{\mathrm{cr}}$ is varied, and the free-space $\lambda$ is used. This summary can be used as a design template for different antenna specifications. A good agreement between the numerical simulation and approximated theory can be observed.

\section{Scattering Parameters}

In Figure 8, scattering parameters of the antenna are measured which include the reflection coefficient and coupling, respectively. In Figure 8a, the measured reflection coefficient for all three array elements shows a 


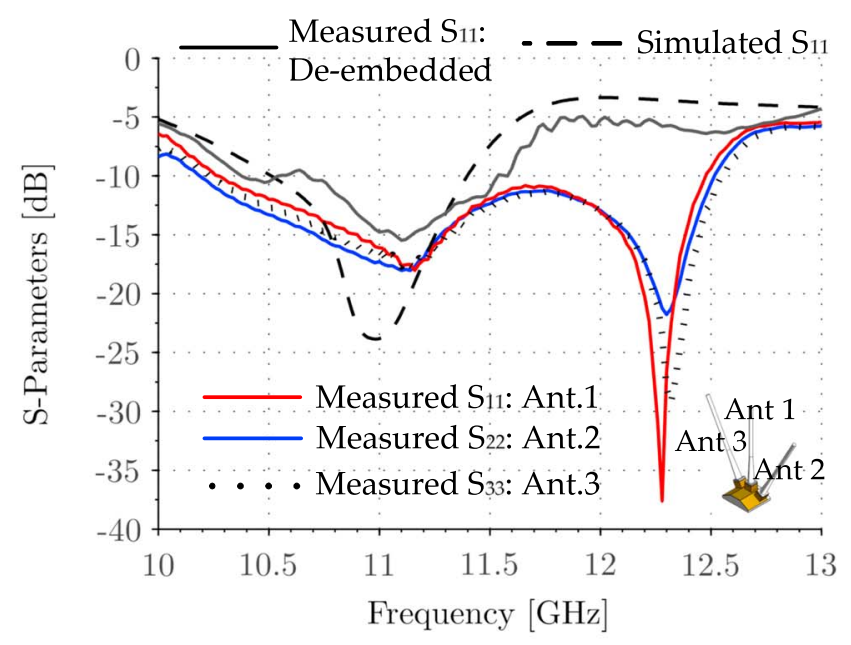

(a)

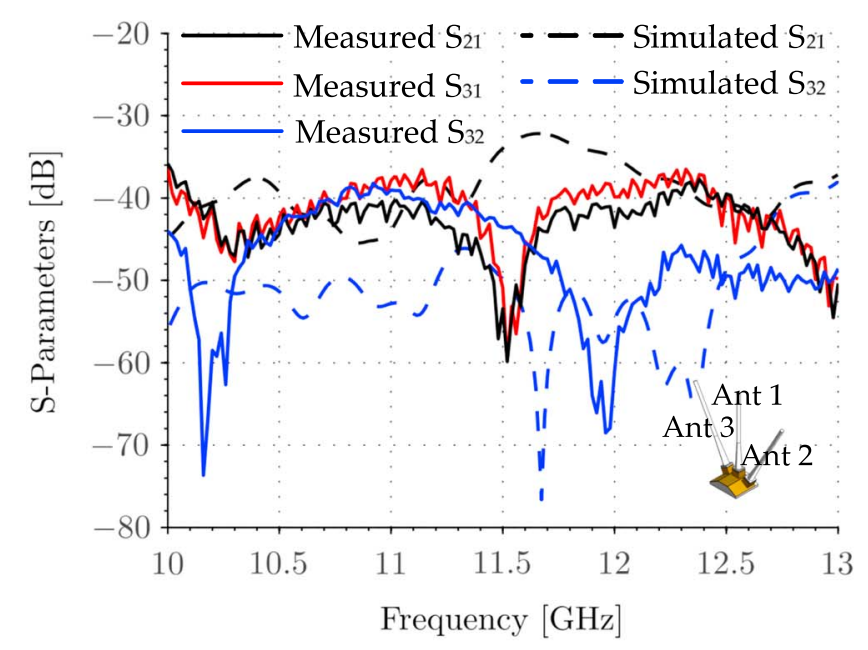

(b)

Figure 8. Comparison between the simulation and measurement for (a) the reflection coefficient $S_{n n}$ and (b) coupling $S_{m n}$ for $m \neq n$. resonance at $11.2 \mathrm{GHz}$ which is in a good agreement with the simulation (i.e., at $11 \mathrm{GHz}$ ). This frequency shift of about $1.8 \%$ results from (1) permittivity variation and homogeneity of the carrier substrate and the rods material and (2) manufacturing accuracy.

The manufacturing accuracy is largely responsible for the $8 \mathrm{~dB}$ difference between the simulated and measured antenna's reflection coefficient at $11.2 \mathrm{GHz}$. The reported $\pm 0.1 \mathrm{~mm}$ profile tolerance from the manufacturer may cause this difference, particularly for the profile length of the feeding line below the patch.

At $12.3 \mathrm{GHz}$, there is a resonance dip which is caused by the soldering of the SMA connector. The cause of this peak can be shown by performing the through-reflect-line (TRL) calibration. This calibration fixture needs to be designed specifically for this antenna, and the manufactured fixture is shown in Figure 9a. The calibration can deembed the soldering, via transition, and SMA connector from the measured antenna system. In other words, the TRL calibration creates a new reference line in the measurement. Thereby, after calibration, what is measured is only the antenna section. This calibration is performed using the vector network analyzer (VNA). After this calibration is performed, the dip at $12.3 \mathrm{GHz}$ is removed as shown in the figure. Subsequently, the antenna's impedance bandwidth of $800 \mathrm{MHz}$ is obtained.

The coupling between antenna elements is measured and shown in Figure $8 \mathrm{~b}$. The simulated and measured results are in a good agreement, especially between close rods (e.g., between tilted and upright rods). The coupling of $-40 \mathrm{~dB}$ at $11.2 \mathrm{GHz}$ is considered sufficiently low for switched-beam operation. This value is actually limited by isolation performance of the RF-MEMS switch which is $20 \mathrm{~dB}$. Furthermore, the coupling between far rods is $-40 \mathrm{~dB}$ while the simulation result gives around $-50 \mathrm{~dB}$. For this relatively weak signal, the impact of the VNAs noise floor becomes significant for the measurement accuracy.

A parametric study of the coupling for different angular position $\theta$ s between the antenna element (at $11 \mathrm{GHz}$ ) is depicted in Figure 10a. As can be observed, the coupling between $30^{\circ}$-tilted antenna elements is around $-47 \mathrm{~dB}$. For $\theta>60^{\circ}$, the coupling increases owing to the fact that the CPW line at the backside of the PCB electromagnetically couples with the neighboring CPW line.

\subsection{RF-MEMS Switch}

In the demonstration of the switched-beam rod antenna array, the SPDT RF-MEMS switch is employed. An evaluation board of this RF-MEMS switch (RMSW 220HP) from Radant MEMS is displayed in Figure 9b. This RF-MEMS switch has the operating frequency from DC to $14 \mathrm{GHz}$. Due to this limited upper frequency of the 


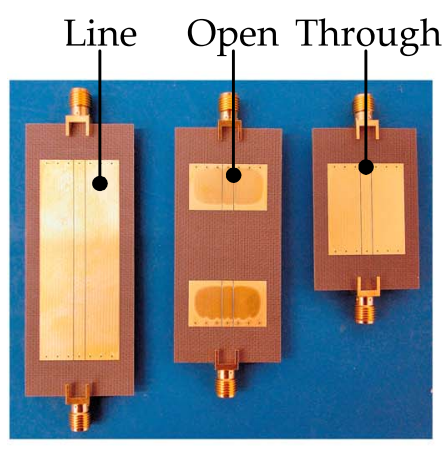

(a)

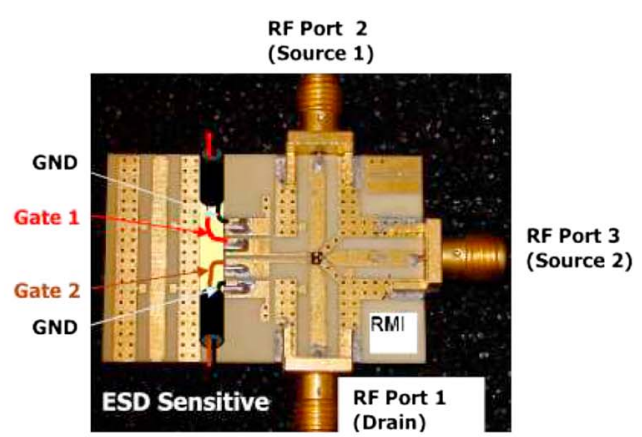

(b)

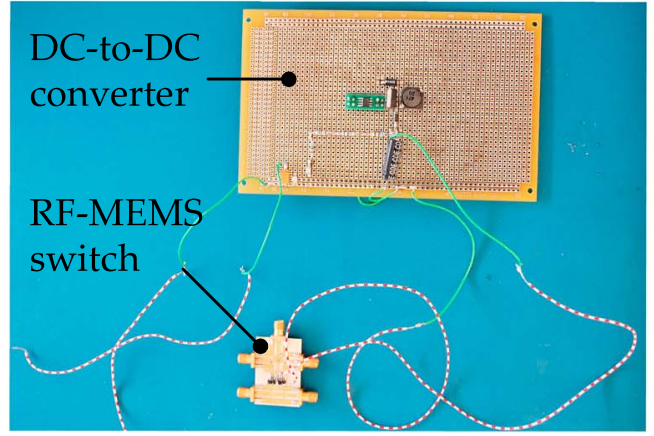

(c)

Figure 9. (a) Line, open, and through configurations for the TRL calibration of the transitions, (b) Radant MEMS Switch (RMSW) 220HP evaluation board, and (c) MAX774 DC-to-DC converter used in the measurement setup for actuating the MEMS switch.

available RF-MEMS switch, the millimeter-wave antenna is demonstrated at $11 \mathrm{GHz}$ as a proof-of-concept switched-beam antenna.

The structure of this evaluation board consists of one RF input and two RF outputs. Performance of the switch is usually provided by the manufacturer. Nonetheless, note that the manufacturer's performance report is measured only for the RF-MEMS, without considering the presence of the SMA connectors, soldering, bondwires, and microstrip line. The source of the actuation voltage can be given by either Gate 1 or Gate 2 for the signal flow in $R F_{\text {out }} 1$ or $R F_{\text {out }} 2$, respectively.

Before this RF-MEMS board is connected to the antenna, a characterization is performed. Some results for this measurement are reported in Figures $11 \mathrm{a}$ and $11 \mathrm{~b}$ for $R F_{\text {out }} 1$ or $R F_{\text {out }} 2$, respectively. It can be observed that $R F_{\text {out }} 1$ has a better performance than $R F_{\text {out }} 2$. Finally, the RF-MEMS needs to be actuated with the $90 \mathrm{~V}_{\mathrm{DC}}$. Therefore, a DC-DC converter is assembled based on the MAX774 adjustable controller from Maxim IC (see Figure 9c). The controller takes $a+5-V_{D C}$ input and converts it to $a-90-V_{D C}$ output. To build a commercialized MEMS, this converter is later on integrated into a chip together with the MEMS structure.

Eventually, Figure 10b shows the scattering parameters of the combined antenna and the RF-MEMS switch board. Note that this measured value includes the influence of the soldering and SMA connector. Hence, the multiple reflections between those discontinuities cause the ripply scattering behavior across the frequency band. Nonetheless, the reflection coefficient is $<-10 \mathrm{~dB}$ for the whole bandwidth of interest, which ensures the maximum power delivery from the input RF-MEMS port to the antenna.

\section{Radiation Pattern}

In this section, the radiation pattern of the rod antenna is discussed. The choice of dielectric material is of importance in determining the radiation pattern of the antenna. For instance, Figure 10c provides an overview of the measured pattern when Teflon $\left(\varepsilon_{r}=2.1\right)$ in comparison with polystyrene $\left(\varepsilon_{r}=2.53\right)$ is used for the rod material. This Teflon rod has the optimal dimensions of the polystyrene rod, for a fair comparison. The rod made from the Teflon, which has a lower relative dielectric constant than the polystyrene, produces 


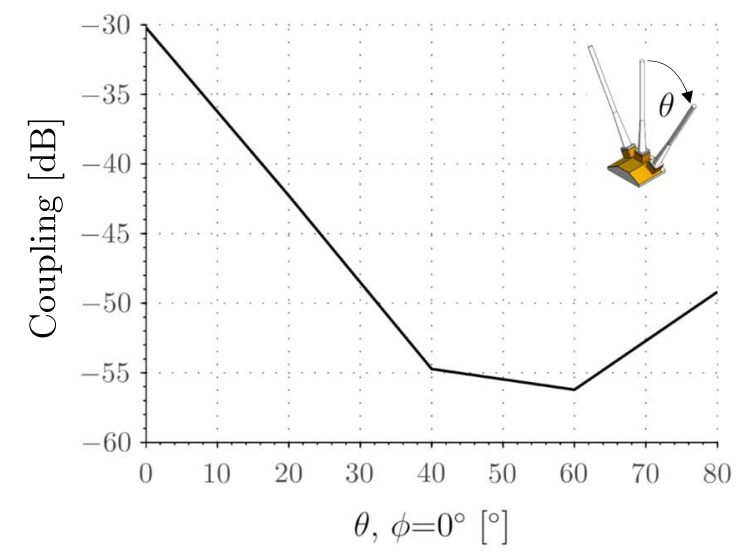

(a)

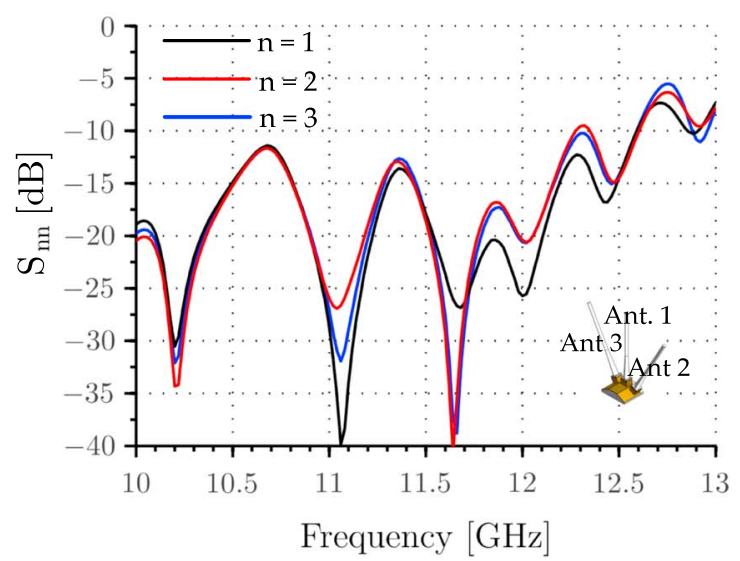

(b)

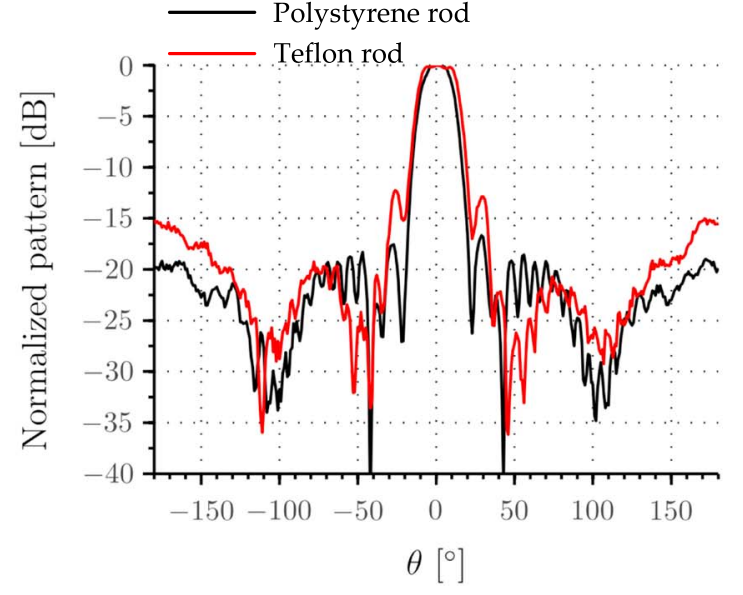

(c)

Figure 10. (a) Simulated coupling between the closest antenna element for different angular position $\theta \mathrm{s}$, (b) measured reflection coefficient for the combined antenna and RF-MEMS switch board, and (c) comparison of the normalized radiation pattern for different rod materials (i.e., different $\varepsilon_{r}$ ).

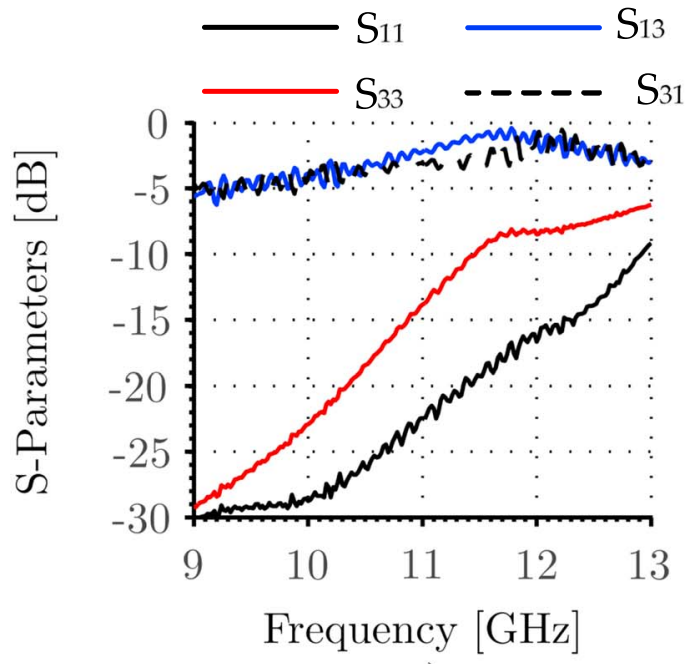

a)

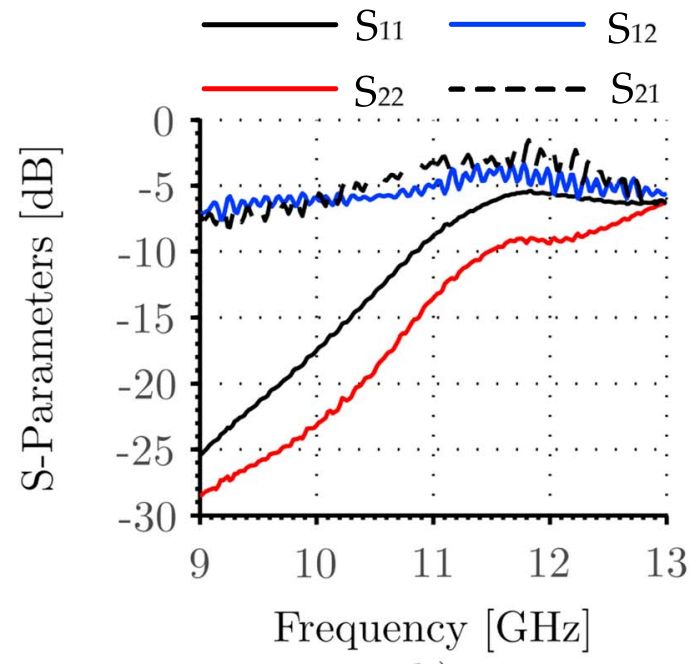

b)

Figure 11. Measured scattering parameters for both (a) $R F_{\text {out }} 1$ and (b) $R F_{\text {out }} 2$ of the RF-MEMS switch. $S_{11}, S_{22}$, and $S_{33}$ are reflection coefficients, and $S_{13}, S_{31}, S_{12}$, and $S_{21}$ are transmission coefficients. 


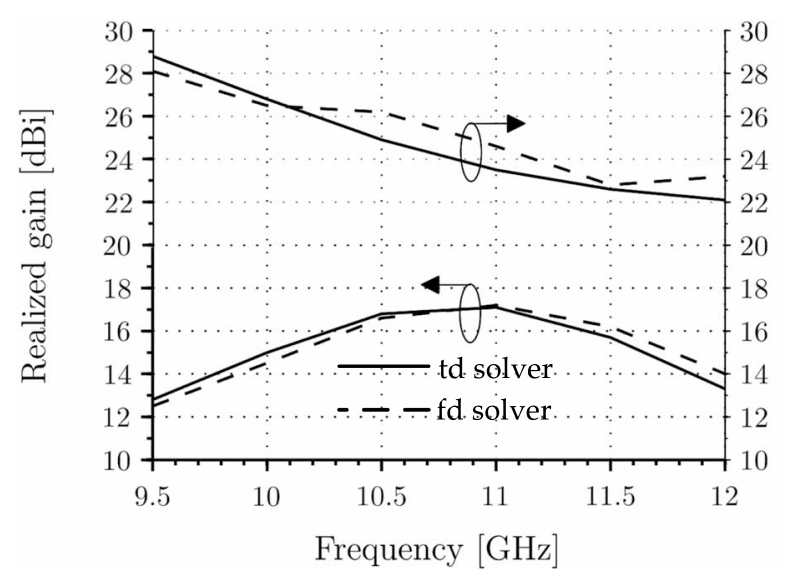

(a)

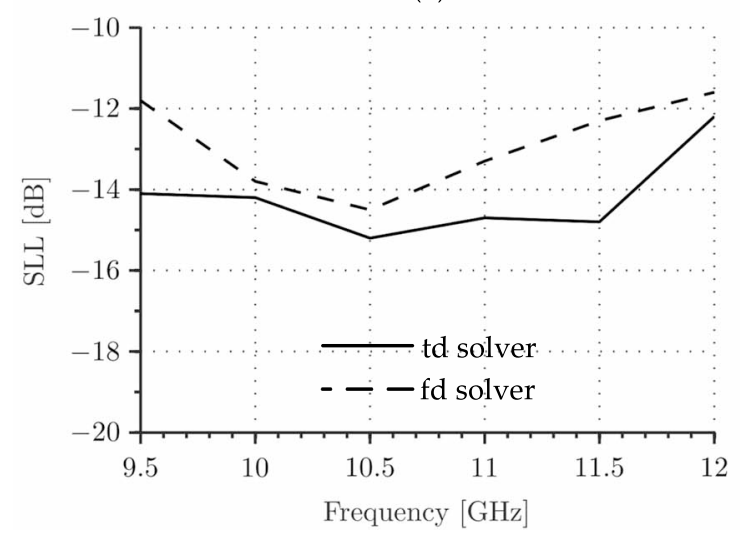

(b)

Figure 12. Simulated results of (a) the realized gain, HPBW, and (b) SLL of the single rod antenna.

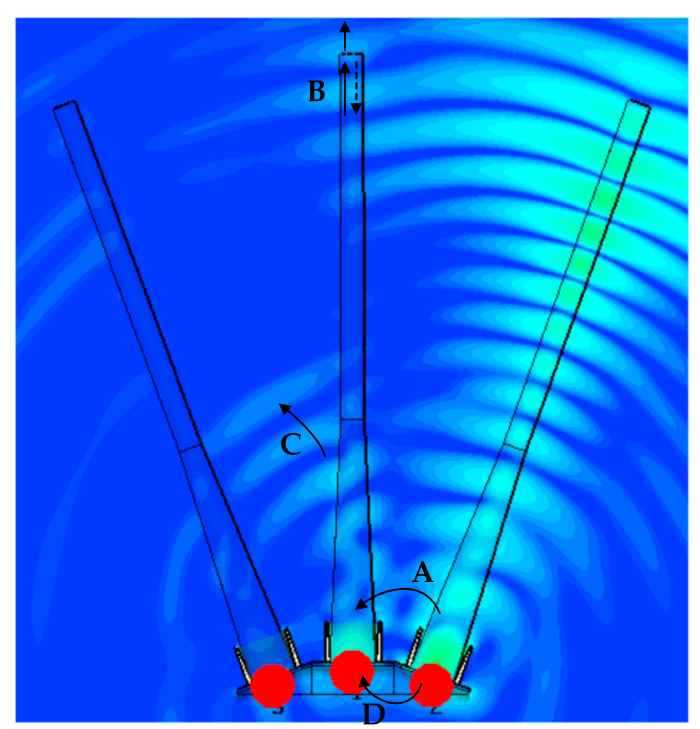

$\mathrm{dB} \mu \mathrm{V} / \mathrm{m}$

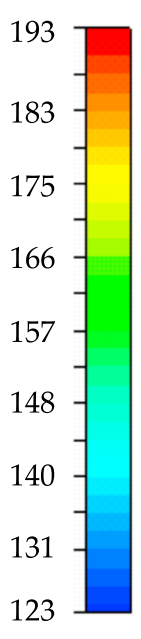

Figure 13. Cross-sectional electric field of the switched-beam rod antenna. Excitation is only applied to the right antenna (i.e., Antenna 2). larger HPBW and SLL. This shows that for the same rod dimensions, the polystyrene rod can guide and focus the electromagnetic wave better than the Teflon rod. The Teflon rod can have a similar performance as the polystyrene rod if the dimensions are changed and optimized, e.g., the diameter is increased.

\subsection{Simulation-Based Radiation Performance}

Figure 12 shows the simulated realized gain, HPBW, and SLL of the single polystyrene rod antenna. The design and simulation are done using a full-wave electromagnetic simulator, namely, CST Microwave Studio. Both time and frequency domain solvers are employed to analyze the antenna structure. The time domain or transient solver has the advantage in terms of computation resources needed due to the electrically large dielectric structure. However, the parallel plate construction between the waveguide and the ground plane may exhibit resonance with high $\mathrm{Q}$ factor. In this case, the frequency domain solver may outperform the latter in terms of computation accuracy and resources. Therefore, the result with the frequency domain solver is also presented here to justify the accuracy of the time domain solver result.

The realized gain has taken into account the presence of the mismatch and ohmic losses. This ohmic loss is caused from the heat loss of the electromagnetic wave in both dielectric and metallic materials during its propagation. The realized gain of the antenna obtained from both solvers is $17 \mathrm{dBi}$ at $11.2 \mathrm{GHz}$. However, it can be seen that HPBW obtained using the time domain solver is around $23^{\circ}$ compared to $24^{\circ}$ using the frequency domain solver. The discrepancy is negligible in a way that both solvers work optimally. More discrepancy may be observed in the SLL. At $11.2 \mathrm{GHz}$, the SLL using the time domain solver is $-13 \mathrm{~dB}$ while the one using another solver is 


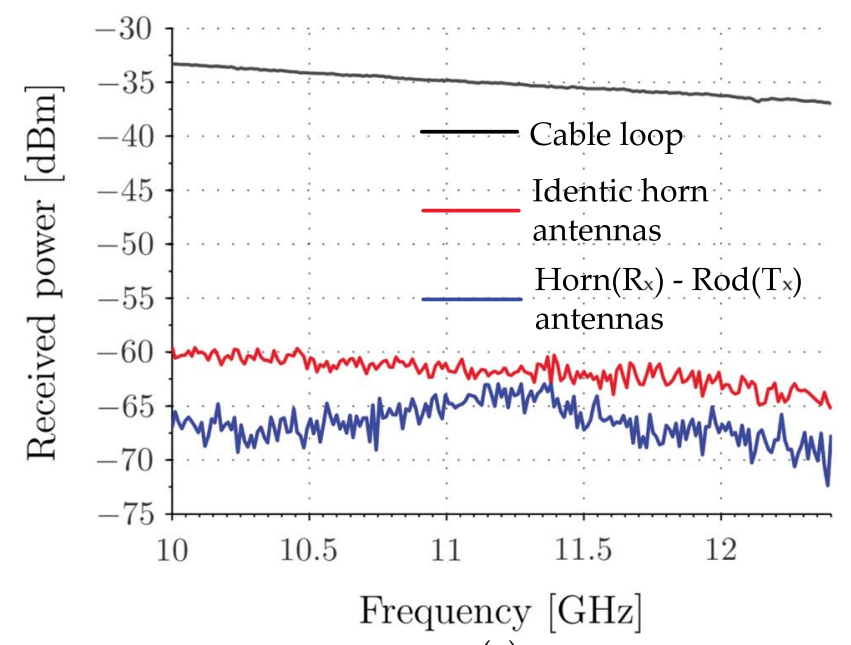

(a)

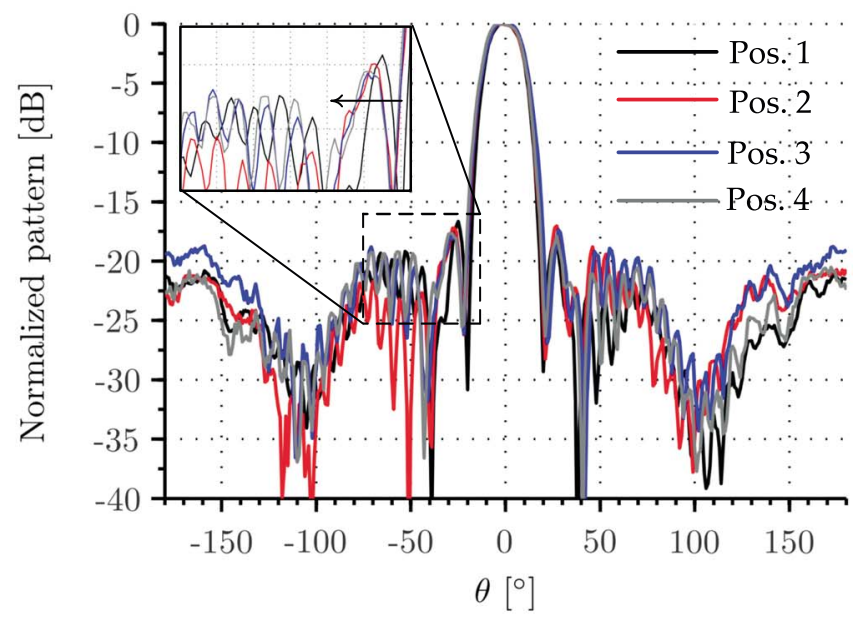

(b)

Figure 14. Measurement preparation: (a) Cable loss contribution in the measurement and (b) comparison of the sidelobes for different measurement distances, for the anechoic-chamber characterization.
$-15 \mathrm{~dB}$ and remains constant up to $11.5 \mathrm{GHz}$ before the SLL degrades.

The SLL is of great importance for avoiding the interception (or generation) of the interference in the wireless environment. Some consumer-based communication systems are often more interference limited than noise limited. The remaining simulated result in this paper will be presented based on the time domain solver.

Figure 13 shows the cross-sectional electric field when the excitation is given at the port of the Antenna 2. The coupling to the neighboring rod will be discussed here. The metallic waveguide is employed in order to minimize coupling between rods. However, a minor coupling is still present as shown in $A$. B in the figure is the region where waves might be reflected back toward the patch of the corresponding rod. The reflection occurs because of the different wave impedance inside the rod and in the free space. C exemplifies the refracted wave instead of the internally reflected wave inside that neighboring rod. $D$ is the mechanism of how the coupling may also occur between the transmission line. Eventually, the majority of the power is guided along the rod of the Antenna 2 showing the feasibility of this rod for switched-beam operation. The maximum electric field is, however, not visible in this figure because the field with that magnitude occurs in the transmission line close to the excited port.

\subsection{Measurement Preparation}

The pattern comparison using a standard gain horn is employed to determine the absolute gain of the rod antenna. In order to verify its accuracy, the measured gain pattern will also be compared with the simulated gain pattern. Figure 14 shows some results that are useful for performing the postprocessing calculation after the measurement. In Figure 14a, the cable loop contributes to the total loss in the amount of $35 \mathrm{~dB}$ at $11.2 \mathrm{GHz}$. This value can be added to the measured power. The transmitted power is $-10 \mathrm{dBm}$. Using the Friis equation in the path loss model, while the distance between two identical horns is $2.64 \mathrm{~m}$, the calculated gain of the horn antenna using the information in the red curve is $17.5 \mathrm{dBi}$ at $11.2 \mathrm{GHz}$. The typical received power when the rod antenna is used for replacing one of the two identical horns is shown in the blue curve. In this way, the gain pattern of the rod antenna can be obtained.

In Figure 14b, the normalized radiation pattern for different measurement distances is depicted. The distance is increased from position 1 to position 4, as indicated by the small arrow in the enlarged picture. The position here corresponds to the position of the horn antenna. The corresponding received power is also mentioned in the figure. The ripple in sidelobes is observed to be shifted for different measurement positions. This is due to the existence of reflections from the wall in the measurement chamber. These 


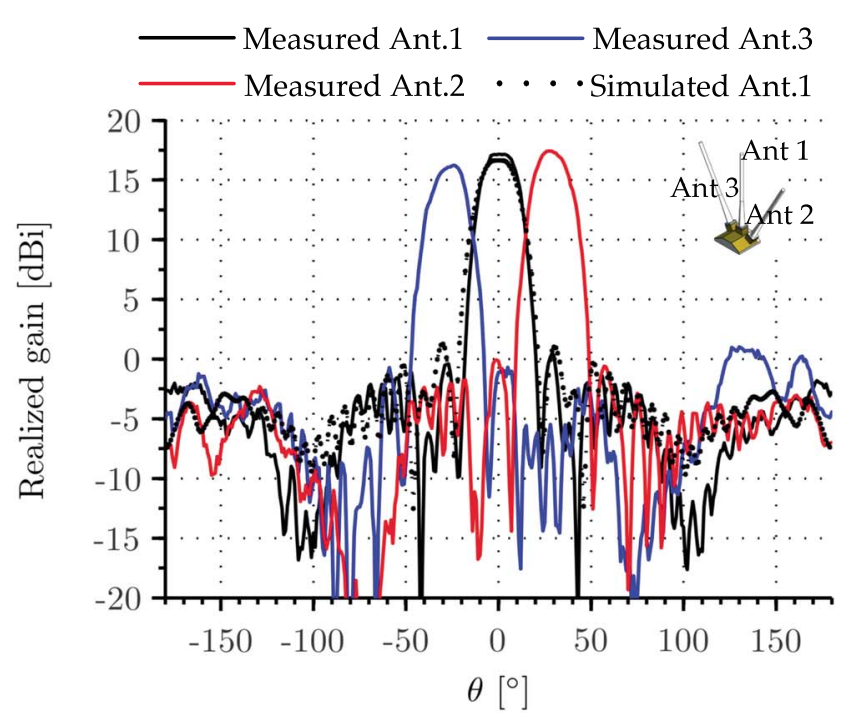

(a)

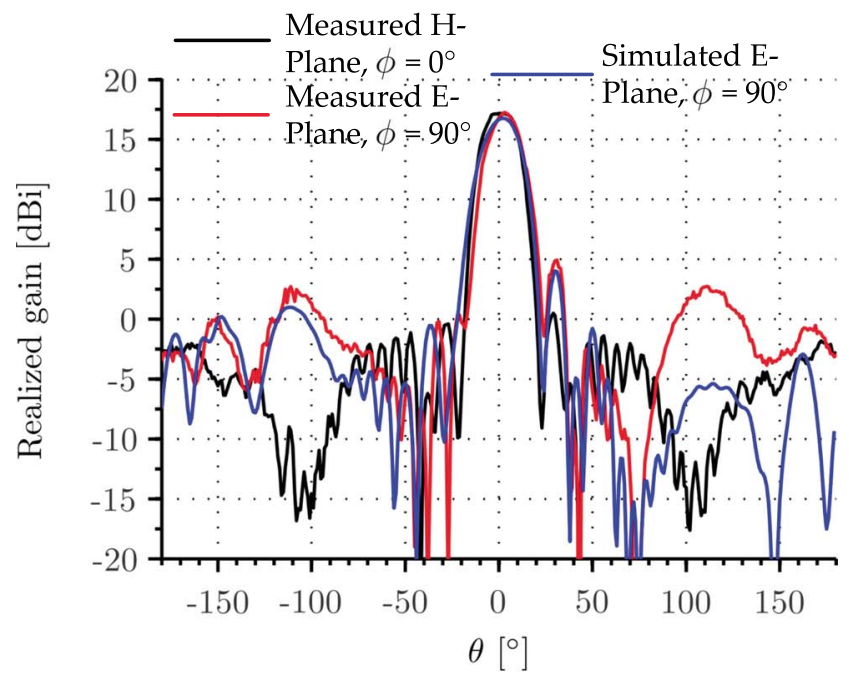

(b)

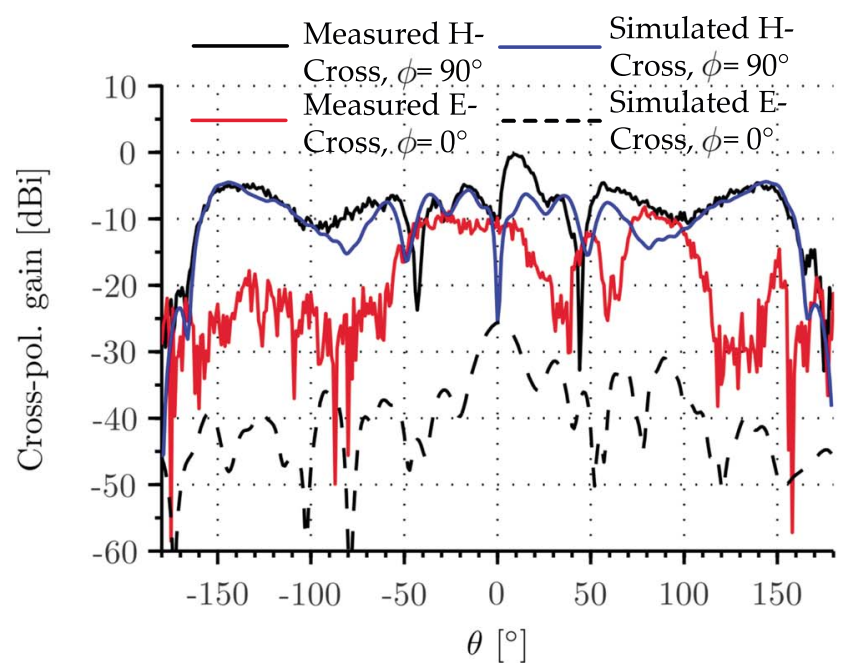

(c) reflections have a constructive and destructive behavior over the measurement angle, and its influence predominates in the sidelobe pattern. Several attempts have been done to minimize this effect, e.g., by covering more absorbers in the potential wall region and also in the measurement fixture.

\subsection{Measurement Result}

The measured radiation pattern and realized gain in the $\mathrm{H}$-plane for each antenna element are depicted in Figure 15a. The measured radiation pattern is in a good agreement with the simulated pattern. The gain of the measured antenna is around $17 \mathrm{dBi}$ at $11.2 \mathrm{GHz}$. The gain of the Antenna 3 is slightly inferior in comparison with other antennas. This difference, which is less than $1 \mathrm{~dB}$, results from manufacturing tolerances of the rod. It has been reported by the manufacturer that the inaccuracy of $1.5 \mathrm{~mm}$ in the rod diameter exists. This deformation mainly occurs at the bottom of the rod. The reason is that a wide cross section of the rod may allow the air fills between polystyrene materials during the molding process. During the process, the temperature decreases, and a reduced diameter occurs at the rod base.

The measured HPBW for left, upright, and right rod is $20^{\circ}, 22^{\circ}$, and $22^{\circ}$, respectively. In the simulation, the HPBW is $22.8^{\circ}, 22.9^{\circ}$, and $22.8^{\circ}$, respectively. The measured SLL is also as expected, which is around $-15 \mathrm{~dB}$. Important to note that, for all elevation angles, the SLL of each rod antenna is smaller than $-14 \mathrm{~dB}$. As mentioned earlier, this low SLL ensures that the interference from the wireless environment will not be intercepted by this antenna array.

Figure 15. Measured and simulated $\mathrm{H}$-plane radiation patterns of the nonplanar rod antenna array. (b) Comparison of copolarized radiation patterns for $\phi=0^{\circ}$ and $\phi=90^{\circ}$ plane. (c) Comparison of cross-polarized radiation patterns for $\phi=90^{\circ}$ and $\phi=0^{\circ}$ plane. 


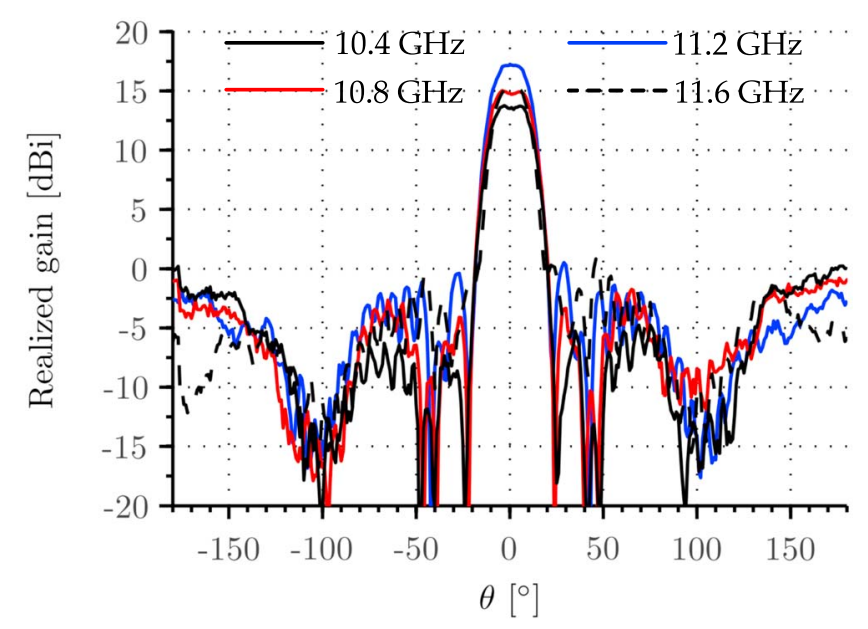

Figure 16. Measured H-plane radiation pattern for different frequencies.
Moreover, it also ensures that the antenna will not generate undesired interference. The backlobe is minor, and its measured result is in accordance with the simulated result.

Copolarized and cross-polarized radiation patterns are also measured and compared with the pattern for another principle plane in Figures $15 \mathrm{~b}$ and $15 \mathrm{c}$. The measured SLL is degraded in the E-plane which becomes $-12 \mathrm{~dB}$, and this result has been confirmed by the simulation. The cause is the diffraction of the surface wave at the edge of the PCB. To eliminate this, a proper grounding structure or pins should be added and distributed along the edge of the PCB. Moreover, at

$\theta= \pm 110^{\circ}$, the minor radiation from the finite ground (FG) CPW's discontinuities can be seen. Basically, the measurement of the cross-polarized gain pattern is also in a good agreement with the simulation. Nevertheless, the measured E-cross pattern has a significant difference with the simulated one albeit having the similar shape. This difference is attributed to the dynamic range of the used instrument, i.e., VNA, with the provided long cable. Generally, uniformity of the measured radiation pattern for both $\phi=0^{\circ}$ and $90^{\circ}$ plane can be concluded.

The measured radiation pattern for different frequencies is summarized in Figure 16. For instance, at 10.4 and $11.6 \mathrm{GHz}$, the achieved realized gain is 14.3 and $15.4 \mathrm{dBi}$, respectively. Although it is not mentioned here for brevity, the (normalized) radiation pattern is almost uniform at the frequency band (i.e., 10.4 up to $11.5 \mathrm{GHz})$.

\section{System Characterization: RF-MEMS Switch and Antenna Array}

The combined antenna and RF-MEMS switch will be explained in this section. Performance of the antenna system is measured and reported. The measurement setup for this switched-beam operation is shown in Figure 17. A DC power supply is used to provide $+5-V_{D C}$ to the DC-DC converter. As mentioned earlier, the

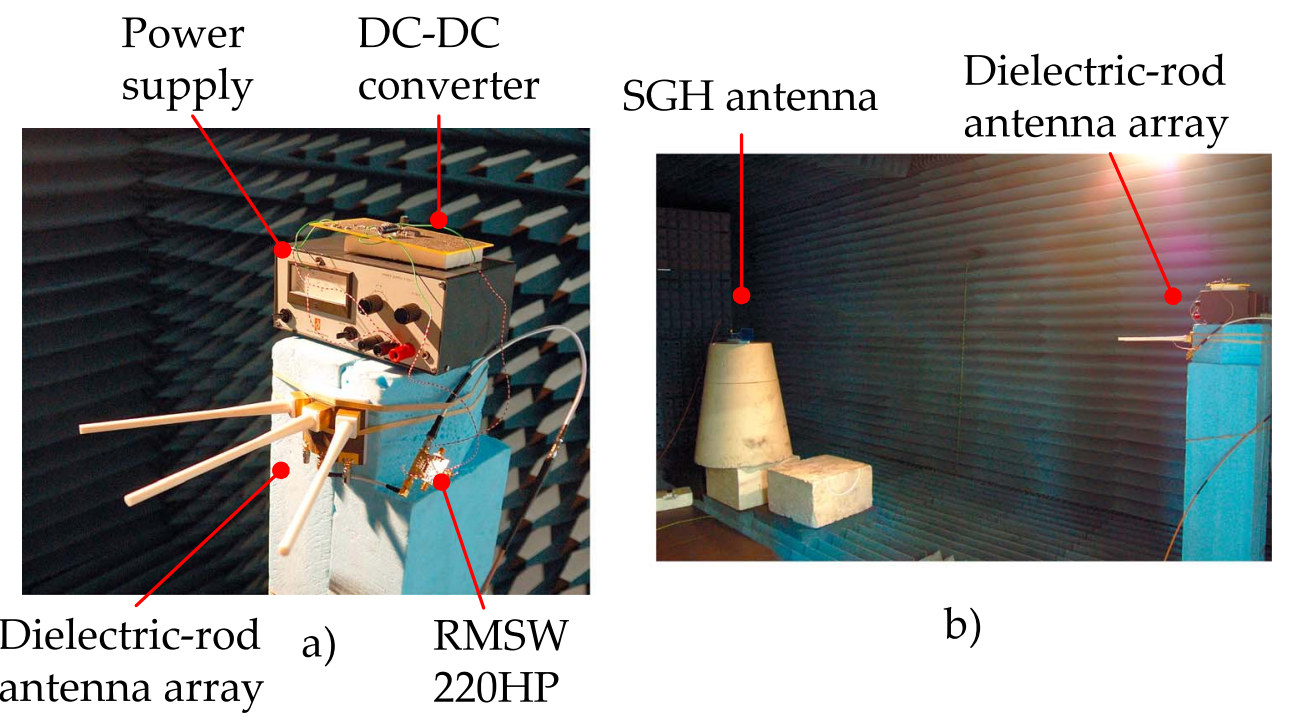

Figure 17. (a) Measurement setup for switched-beam operation and (b) radiation pattern measurement in the anechoic chamber. 


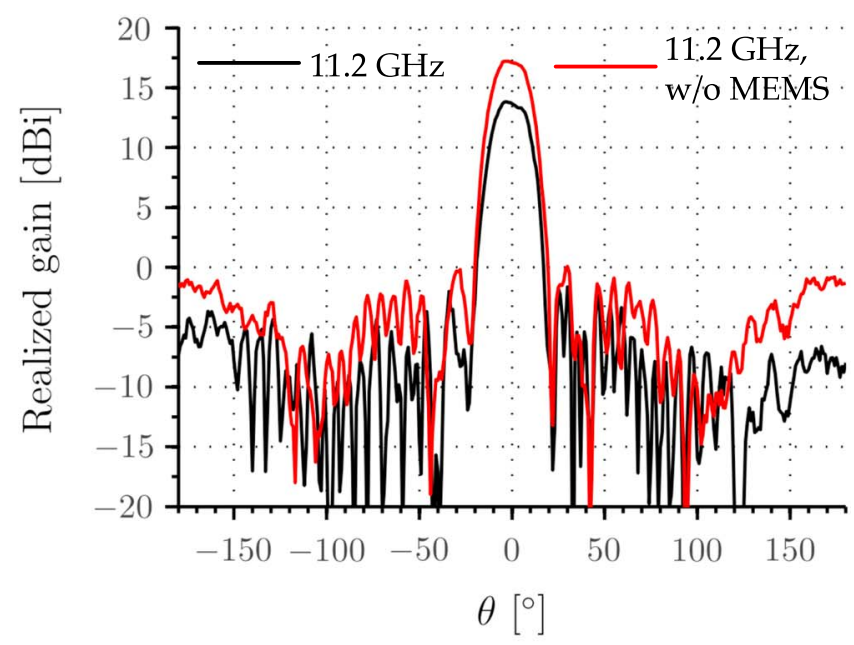

(a)

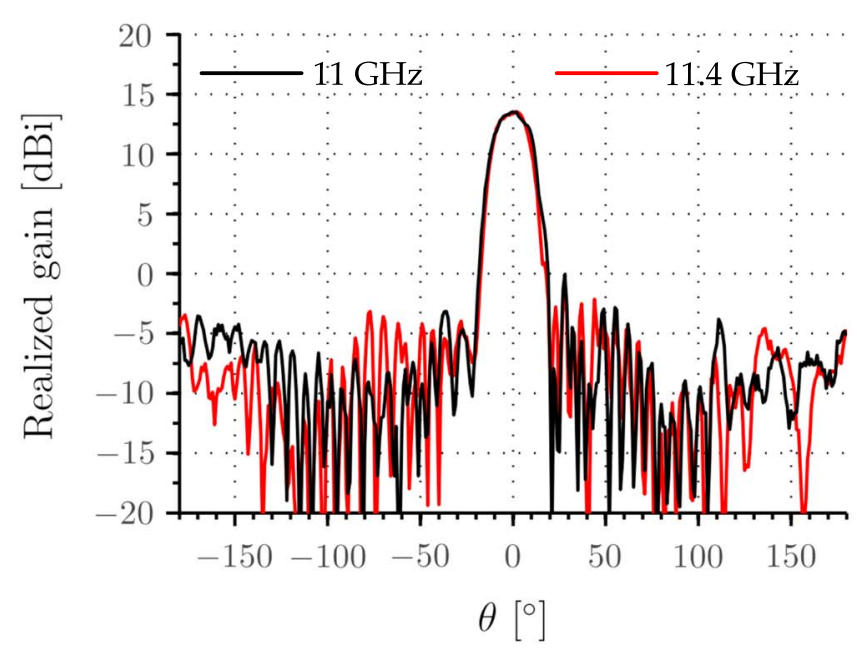

(b)

Figure 18. (a) Comparison of measured H-plane radiation patterns of the antenna array with and without the RF-MEMS switch. (b) Measured radiation pattern of the combined rod antenna array and RF-MEMS switch for different frequencies. For brevity, the result is only shown for Antenna 1.

\section{agreement with the simulated antenna}

pattern. At $11.2 \mathrm{GHz}$, the measured antenna with the RF-MEMS switch has $13.5 \mathrm{dBi}$ realized gain, $-15 \mathrm{~dB}$ SLL, $22^{\circ} \mathrm{HPBW}$, and $7.3 \%$ bandwidth. The measured coupling between adjacent antenna elements is better or equal to $-40 \mathrm{~dB}$ across the bandwidth. The measured antenna gain without the RF-MEMS switch is $17 \mathrm{dBi}$. The switched-beam antenna array using the dielectric rod element has demonstrated the radiation pattern with high gain and narrow beamwidth. The other advantage of this antenna is its uniform performance for each element in the conformal structure. In this way, the beam at the largest angle of the scan range will not be severely degraded, like in the case of the planar patch array. It is definitely very advantageous to have a broad scan range antenna with uniform performance, remembering that the International Telecommunication Union criterion for the maximum allowed equivalent isotropic radiated power of an antenna is determined from how large the maximum gain of that antenna can be during operation.

\section{References}

Ando, T., J. Yamauchi, and H. Nakano (2003), Numerical analysis of a dielectric rod antenna-Demonstration of the discontinuity-radiation concept, IEEE Trans. Antennas Propag., 51(8), 2007-2013, doi:10.1109/TAP.2003.814731.

Ando, T., I. Ohba, S. Numata, J. Yamauchi, and H. Nakano (2005), Linearly and curvilinearly tapered cylindrical-dielectric-rod antennas, IEEE Trans. Antennas Propag., 53(9), 2827-2833, doi:10.1109/TAP.2005.854551. 
Bird, T., A. Weily, and S. Hanham (2008), Antennas for future very-high throughput wireless LANs, in IEEE Antennas and Propagation Society International Symposium, AP-S 2008, 5-11 July 2008, San Diego, Calif., pp. 1-4, IEEE, doi:10.1109/APS.2008.4619477.

Detrick, D. L., and T. J. Rosenberg (1990), A phased-array radiowave imager for studies of cosmic noise absorption, Radio Sci., 25(4), 325-338, doi:10.1029/RS025i004p00325.

Hanham, S., and T. Bird (2008), High efficiency excitation of dielectric rods using a magnetic ring current, IEEE Trans. Antennas Propag., 56(6), 1805-1808, doi:10.1109/TAP.2008.923335.

Hanham, S., T. Bird, A. Hellicar, and R. Minasian (2011), Evolved-profile dielectric rod antennas, IEEE Trans. Antennas Propag., 59(4), 1113-1122, doi:10.1109/TAP.2011.2109689.

Huang, K.-C., and D. Edwards (2006), $60 \mathrm{GHz}$ multibeam antenna array for gigabit wireless communication networks, IEEE Trans. Antennas Propag., 54(12), 3912-3914, doi:10.1109/TAP.2006.886575.

Huang, K.-C., and Z. Wang (2006), V-band patch-fed rod antennas for high data-rate wireless communications, IEEE Trans. Antennas Propag., 54(1), 297-300, doi:10.1109/TAP.2005.861521.

Jordan, J. W., B. K. Sternberg, and S. L. Dvorak (2009), Development and validation of a low-frequency modeling code for high-moment transmitter rod antennas, Radio Sci., 44, RS6008, doi:10.1029/2008RS004010.

Karttunen, A., J. Ala-Laurinaho, R. Sauleau, and A. Raisanen (2013), Extended hemispherical integrated lens antenna with feeds on a spherical surface, paper presented at 7th European Conference on Antennas and Propagation (EuCAP), Göteborg, Sweden, 8-12 April 2013, pp. 2539-2543.

Kraus, J., and R. Marhefka (2002), Antennas for All Applications, 3rd ed., McGraw Hill, New York.

Kumar, C., V. V. Srinivasan, V. K. Lakshmeesha, and S. Pal (2010), Design of short axial length high gain dielectric rod antenna, IEEE Trans. Antennas Propag., 58(12), 4066-4069, doi:10.1109/TAP.2010.2078457.

Michiels, B., I. Bogaert, J. Fostier, J. Peeters, and D. De Zutter (2011), Simulation of a Luneburg lens using a broadband multilevel fast multipole algorithm, Radio Sci., 46, RS2003, doi:10.1029/2010RS004510.

Ouyang, J. (2011), A circularly polarized switched-beam antenna array, IEEE Antennas Wirel. Propag. Lett., 10, 1325-1328, doi:10.1109/LAWP.2011.2176308.

Rebeiz, G. M. (2003), RF MEMS Theory, Design, and Technology, Wiley, Hoboken, N. J.

Sanada, A. (2008), Two-dimensional beam steering array using planar eight-element composite right/left-handed leaky-wave antennas, Radio Sci., 43, RS4S23, doi:10.1029/2007RS003800.

Whitman, G., C. Pinthong, W.-Y. Chen, and F. Schwering (2006), Rigorous TE solution to the dielectric wedge antenna fed by a slab waveguide, IEEE Trans. Antennas Propag., 54(1), 101-114, doi:10.1109/TAP.2005.861533.

Wilson, A., J. J. Nel, M. J. Mathews, and P. H. Stoker (2001), Direct measurements on imaging riometer antenna array beam directivities, Radio Sci., 36(6), 1531-1543, doi:10.1029/2000RS002509.

Zelenchuk, D., A. Martinez-Ros, T. Zvolensky, J. Gomez-Tornero, G. Goussetis, N. Buchanan, D. Linton, and V. Fusco (2013), W-band planar wide-angle scanning antenna architecture, J. Infrared Millimeter Terahertz Waves, 34(2), 127-139, doi:10.1007/s10762-013-9960-z.

Zhang, Y. S., and W. Hong (2012), A millimeter-wave gain enhanced multi-beam antenna based on a coplanar cylindrical dielectric lens, IEEE Trans. Antennas Propag., 60(7), 3485-3488, doi:10.1109/TAP.2012.2194646.

Zucker, F. J. (2007), Antenna Engineering Handbook, McGraw-Hill, New York. 